\title{
MICRO BUBBLE FORMATION AND BUBBLE DISSOLUTION IN DOMESTIC WET CENTRAL HEATING SYSTEMS
}

\author{
Andrew M. FSADNI; Yunting GE
}

\begin{abstract}
UK are known to originate from wet domestic central heating systems. Contemporary systems make use of very efficient boilers known as condensing boilers that could result in efficiencies in the $90-100 \%$ range. However, research and development into the phenomenon of micro bubbles in such systems has been practically non-existent. In fact, such systems normally incorporate a passive deaerator that is installed as a 'default' feature with no real knowledge as to the micro bubble characteristics and their effect on such systems. High saturation ratios are known to occur due to the widespread use of untreated tap water in such systems and due to the inevitable leakage of air into the closed loop circulation system during the daily thermal cycling. The high temperatures at the boiler wall result in super saturation conditions which consequently lead to micro bubble nucleation and detachment, leading to bubbly two phase flow. Experiments have been done on a test rig incorporating a typical $19 \mathrm{~kW}$ domestic gas fired boiler to determine the expected saturation ratios and bubble production and dissolution rates in such systems.
\end{abstract}

\section{INTRODUCTION}

In a domestic central heating system micro bubble formation is the result of water supersaturated with dissolved nitrogen gas, consequently, leading to bubble nucleation on the water side of the boiler primary heat exchanger. Micro bubble nucleation is solely attributed to the presence of gas super saturation levels in the water flowing in the system's closed loop circuit. Long term tests have shown that such systems could result in saturation ratios as high as 1.2 at the boiler wall conditions, while typical under saturation ratios in the system flow line are in the range of 0.89 to 0.98 . Air is mostly absorbed in the system during the cold cycle. At low temperatures, water can absorb the highest quantity of dissolved gasses $[1,2]$. In most systems this occurs during night time when the system's boiler shuts off.

Bubble formation due to supersaturated solutions, is a phenomenon present in a number of industrial processes such as the chemical, pharmaceutical, food and power

Andrew M. Fsadni: Department of Mechanical Engineering, c/o Research Office, School of Engineering and Design, Michael Sterling Building, Brunel University, Uxbridge UB8 3PH, United Kingdom; andrew.fsadni@brunel.ac.uk

Yunting Ge; Department of Mechanical Engineering, Room: H118, Brunel University, Uxbridge, UB8 3PH, United Kingdom; yunting.ge@brunel.ac.uk 
generationindustries. However, most of the research in this area has been purelytheoretical in its nature. Hepworth et al. [3], attributed this lack of research to the difficulties in obtaining reliable experimental bubble nucleation data and to the complex physical parameters that characterise systems where the nucleation phenomenon is observed. This is also due to the inherent difficulties in analysing two phase mechanisms as outlined by Winterton and Munaweera [4].

Data on micro bubble production and dissolution rates in central heating systems is important as a good knowledge of bubble sizes and their distribution is essential for an efficient passive deaeration process. Deaeration is an important feature of such systems as bubbles accumulate in radiators and result in cold spots, thus reducing the heat transfer area of the radiator and the overall system efficiency. Bubbles are also known to result in unwanted noise, blockages and corrosion. Domestic central heating systems amount to $16 \%$ of the carbon dioxide emissions in the UK [5] and consequently an optimised system performance should result in significant environmental benefits.

Hence, a bubbly flow in the circuit's forward flow line results from the detachment of micro bubbles from the boiler wall into the system. Bubbly two-phase flow is characterised by the presence of bubbles of maximum size much less than the containing vessel or duct with bubbles are dispersed in a continuous liquid phase [4]. From our test results no micro bubbles were observed on the return line to the boiler, thus suggesting that micro bubbles dissolve, are deaerated or rise to high points in radiators or vessels while flowing through the system.

Studies on bubble formation in supersaturated solutions done by Wilt [6], Lubetkin and Blackwell [7], Carr et al. [8] and Jones et al. [9,10] all reported that the nucleation rate was a very sensitive function of the degree of super saturation. The authors of the present study do not known of a model that can accurately predict the nucleation rates in solutions with low superstations that may be adapted to more practical systems. Hepworth et al. [3] developed a model with good experimental predictions to predict nucleation rates in dispensed beer where relatively low super saturation levels predominate. This was done through the use of Scriven's bubble growth rate model as adapted by Jones et al. [9] and the force balance model developed by Winterton [11] to predict the bubble detachment radius. However, this model is not considered as adequate for the present study.

Limited consideration has been given in literature to the expected dissolution of free bubbles in turbulent flow with minimal slip. Kress and Keyes [12] investigated the liquid phase controlled mass transfer to bubbles in co-current turbulent pipe flow through a correlation for the Sherwood number. They report that data obtained for the mass transfer in agitated vessels cannot be used directly to predict mass transfer in pipeline flow as lower mass transfer rates are expected in agitated vessels due to the relative ineffectiveness of the turbulence in agitated vessels to enhance the mass transfer process. Lezhnin et al. (2003) [13] considered the dissolution of air bubbles in water flowing in a horizontal pipeline where in contrast to the constant pressure used in the present study, their pressure drops from several bars to the atmospheric one.They classify the mass transfer mechanism in under saturated bubbly flow as turbulent diffusion. Most studies on bubble dissolution in under saturated solutions have been done for isolated gas bubbles and are based on the Epstein and Plesset gas diffusion model. $[14,15,16]$ The theoretical interpretation of these experiments has been based on the consideration of an isolated sphere in spherically symmetrical conditions. Hence, at under 
saturated conditions the bubble dissolves at a rate controlled by the diffusion of gas through the liquid.

In this paper we will analyse the micro bubble production and dissolution rates occurring due to super saturation conditions on the primary heat exchanger wall of a domestic gas fired central heating boiler. Long term tests have shown typical saturation ratios in the range of 1 to 1.2 at the boiler primary heat exchanger wall conditions with under saturation ratios in the flow line in the range of 0.89-0.99.

\section{THEORY}

\subsection{The solubility of gasses in liquids and supersaturated solutions}

Fogg [17] states that the solubility of gases in a liquid is a property of a gas dependent on its partial pressure and on the temperature as well as the nature of the liquid phase. In fact, for most gas-liquid systems there tends to be a linear variation of solubility with the partial pressure as this approaches zero. When defining the solubility of gases, Young et al. [18] highlight the point that the distinction between vapor-liquid equilibria and the solubility of gases in liquids is arbitrary and often the distinction between the two is not clear. This issue arises from the general inability to rigorously distinguish between a gas, a vapor and a liquid. However, Gerrad [1] defines gases as all the elements and compounds having a boiling point at 1 atm at a temperature less than $13^{\circ} \mathrm{C}$. Gas solubility data at standard atmospheric and volumetric conditions is available through a number of publications [2].

Jones et al. [9] defines a supersaturated solution in relation to quantifying the tendency of a system to produce bubbles. They refer to the saturation data as a function of the temperature for the system. A solution could go into the supersaturated state through the increase of its temperature. In fact, point $A$ in Fig. 1 represents a saturated solution at a temperature $T_{A}$ with a saturation mole fraction amounting to $X_{b}$. When the temperature of this solution is increased to $T_{B}$, the solution would be in its supersaturated state while still retaining the previous mole fraction of the dissolved gas content. The desorption of gas from the water then causes the state of the system to move gradually from point $B$ to point $B^{\prime}$ with a new saturation mole fraction equal to $X_{i}$. In view of this, the resultant saturation ratio is defined through the relationship in Eqn. (1);

$$
\alpha=\frac{X_{b}}{X_{i}}
$$

Furthermore, the super saturation ratio is defined as

$$
\sigma=\alpha-1
$$




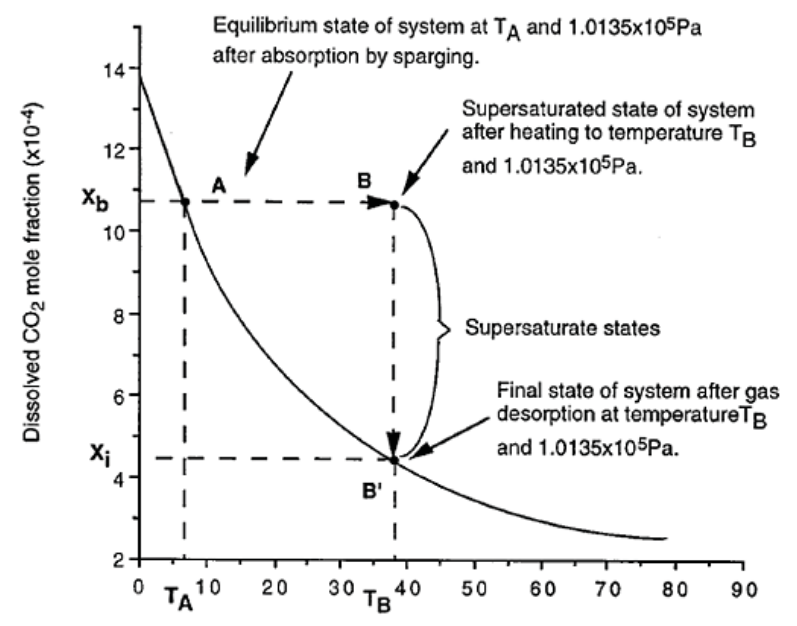

Figure 1: Solubility of carbon dioxide. [10] (p.30).

Our saturation ratio was calculated through the use of Eqns. (3\&4). as done by Lubetkin and Blackwell [7] who calculated the gas concentration in the fluid through the use of the Henry's law as defined by Gerrard [1] The partial gas pressure was calculated by subtracting the vapour pressure from the total dissolved gas pressure.

$$
C_{\text {gas }}=P_{g} X^{T}
$$

The saturation ratio was calculated through the use of Eqn. (1). As shown in Eqn. (4), the ratio of the actual gas concentrations was used where $C_{\text {sat }}$ refers to the maximum gas solubility at the primary heat exchanger wall temperature and pressure or relevant flow line bulk fluid conditions.

$$
\alpha=\frac{C_{g a s}}{C_{s a t}}
$$

\section{$2.2 \quad$ Bubble dissolution models}

Studies done by Kress and Keyes and Lezhnin et al. $[12,13]$ have described the bubble dissolution in turbulent bubbly flow through the application of the Sherwood number, thus capturing the ratio of the convective to the diffusive mass transport through the inclusion of the dimensionless Reynolds and Schmidt numbers. Lezhnin et al., [13] report that four principal correlations are available for the calculation of bubble dissolution in agitated waters and pipe flow. Such correlations are based on a proportionality constant and the power for the Reynolds number, whilst the Schmidt number is calculated at a power of 0.5 for all correlations. Furthermore, they identify the correlation given in Eqn. (5) as the most widely used by researchers investigating bubble dissolution in similar conditions as the present study. Hence, the Sherwood number captures the enhanced bubble dissolution due to the turbulent diffusion characteristics present in turbulent bubbly pipe flow. 


$$
S h=A \frac{d_{b u b}}{d} R e^{0.75} S c^{0.5}
$$

A number of authors have developed numerical models based on the gas diffusion model whereby the time for an initial sphere radiusto dissolve to a radius $R_{x}$ is predicted for isolated bubbles in stagnant under saturated water. $[14,15,16]$. Two principal mechanisms are known to govern the bubble dissolution process, these being the solution of the gas into the liquid at the bubble fluid interface and the diffusion of dissolved gas away from the interface into the outer phase of infinite extent. The former mechanism is much faster when compared to the latter and consequently, the diffusion process is assumed to be diffusion controlled. The advection and diffusion equations of solute in the host liquid are the principal equations used in these analytical models. These models also include the kinematic condition at the moving bubble surface which models the shift in the bubble radius in terms of the diffusion flux.

Epstein and Plesset[14] reported that the effect of the bubble boundary motion as a result of shrinkage introduces a transport term in the diffusion equation which makes it difficult to obtain an analytical solution. Hence, as advection results in a minimal effect on the dissolution time for isolated bubbles, they neglected this effect. They reported that this estimation is accurate, as the concentration of the dissolved gas in the liquid surrounding the bubble is much smaller than the gas density in the bubble. Also, the region in the solution around the bubble is considered to be much larger than the bubble itself. They expressed their model through the differential equation for the dissolution time of a stationary bubble as in Eqn. (6).

Where:

$$
\frac{d R_{o}}{d t}=-B\left[\frac{1}{R}+\frac{1}{(\pi D t)^{1 / 2}}\right]
$$

$$
B=\frac{D\left(C_{E}-C_{0}\right)}{\rho_{g}}
$$

Epstein and Plesset used three constants $\varepsilon, x^{2}$ and $y$ to express Eqn. (1) in dimensionless form as given in the differential Eqn. (7).

Where:

$$
\frac{d \epsilon}{d x}=-\frac{x}{\epsilon}-2 \gamma
$$

$$
\epsilon=\frac{R_{x}}{R_{o}} ; x^{2}=\left[\frac{2 B}{R_{o}^{2}}\right] t ; \gamma=\left[\frac{C_{E}-C_{O}}{2 \pi \rho_{g}}\right]^{\frac{1}{2}}
$$

They further simplified their model through the knowledge that the second term yin Eqn. (7) is small for long dissolution times, thus allowing significant diffusion to take place. Hence, they ignored this term with the result of a simplified analytical dissolution model as in Eqn. (8).

$$
\epsilon^{2}=1-x^{2}
$$




\section{EXPERIMENTAL FACILITY}

A schematic diagram of the experimental set up is shown in Fig. 2. The test rig consists of a Vaillaint eco TEC pro 24 condensing boiler that is connected to $20 \mathrm{~mm}$ (inner diameter) copper tubing which supplies a radiator and a buffer vessel. A condensing boiler is used as this is mandatory equipment for new buildings in most European Union member states [5]. Seven stainless steel sheathed $K$ type thermocouples are used to measure the fluid temperatures along the circuit. Three pressure transducers monitor the system pressure. A fourth pressure transducer monitors the dissolved gas partial pressure in combination with a semi permeable silicone membrane. The partial gas pressure monitoring system requires the water to be cooled to a temperature between 20 and $45^{\circ} \mathrm{C}$. Therefore, as shown in Fig. 2, a tap water cooling heat exchanger was used to cool the system water to a lower temperature.

The system fluid flow rate is monitored through an Electromag 500 Series electromagnetic flow meter. A National Instruments CDAQ-9172 chassis and relevant data modules receive all the signals from the transducers, thermocouples and electromagnetic flow meter. As tabulated in Table 1, four tests were conducted. The first three tests were done to analyse the bubble production rates at the boiler exit, hence using sight glass VSG1, while the Test IV was done to analyse bubble dissolution at a constant under saturation with changing fluid velocities in horizontal pipe flow, thus using sight glasses HSG1\&2. The three system parameters are controlled as follows while the system pressure is set through the use of a nitrogen gas cylinder connected to a standard cylinder regulator.

i The system heating load was varied between a minimum of $7.5 \mathrm{~kW}$ and a maximum of $21.5 \mathrm{~kW}$ through the step increase in the boiler flame settings. The return temperature was maintained constant through the use of the magnetic tap connected to the tap water mains supply line. The heating load is equal to a heat flux ranging between 17 to $50 \mathrm{~kW} / \mathrm{m}^{2}$ on the heat exchanger's wall.

ii The system flow rate or velocity is varied through the use of a ball valve on the supply line. The velocity in the primary heat exchanger tubes was stepped between a minimum $0.39 \mathrm{~m} / \mathrm{s}$ and a maximum of $0.85 \mathrm{~m} / \mathrm{s}$, with the corresponding velocities in the system pipe work in the range of $0.25-0.52 \mathrm{~m} / \mathrm{s}$. This is equal to a system flow rate ranging from 6 to 12.5 litres per minute.

iii Low saturation ratios were achieved through the sudden release in system pressure followed by a subsequent re-pressurisation. High ratios were achieved through the filling of the upper part of the radiator with nitrogen gas. Saturation ratios at the primary heat exchanger wall conditions ranging from 1 to 1.20 , as defined by Jones et al. [9], were achieved while an under saturation ratio of 0.89 was achieved in the flow line between sight glasses HSG1\&2. This range of saturation ratios was established following long term testing on a central heating test rig [18]. 


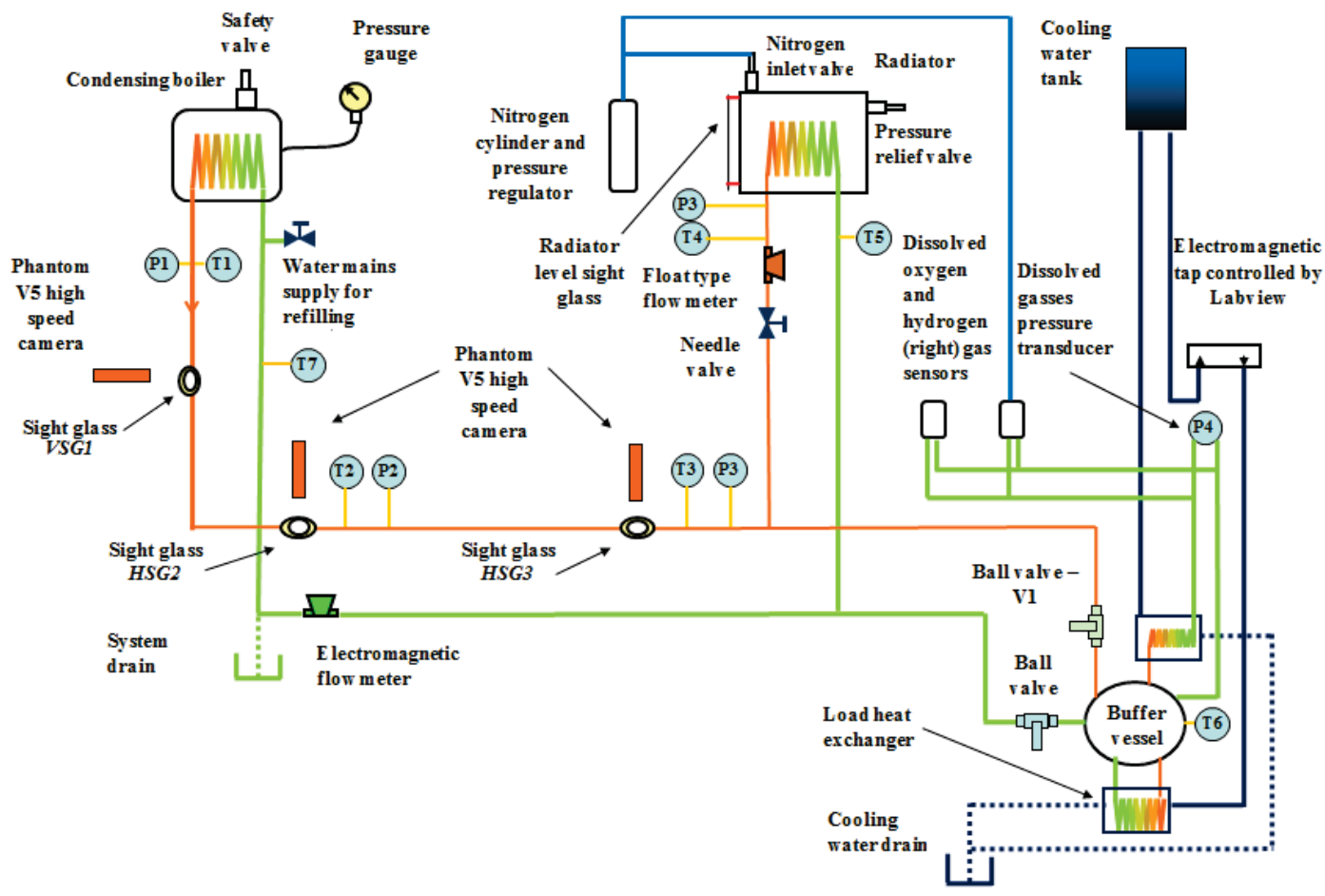

Figure 2: Schematic diagram of experimental set up

Domestic central heating systems make use of tubular primary heat exchangers. The primary heat exchanger design (Giannoni) used in the current study consists of 12 rectangular tubes coiled around the boiler burner in a helical structure. The first 4 tubes at the return end are compartmentalised into a condenser where the flue gases from the gas burner condense on the cold tube surfaces, releasing latent heat, consequently resulting in higher efficiencies. The water side wall temperature of the heat exchanger, used to calculate the saturation ratio at the wall conditions, was calculated through energy balance as given by Eqn. (9).

$$
q=h\left(T_{w}-T_{b}\right)
$$

\begin{tabular}{|c|c|c|c|c|c|c|c|}
\hline Test & $\begin{array}{c}\text { Bulk fluid } \\
\text { velocity in } \\
\text { pipe work } \\
(\mathbf{m} / \mathbf{s})\end{array}$ & $\begin{array}{c}\text { System } \\
\text { pressure } \\
(\text { Bars })\end{array}$ & $\begin{array}{c}\text { System } \\
\text { heating } \\
\text { load } \mathbf{( k W )}\end{array}$ & $\begin{array}{c}\text { Saturation ratio } \\
\text { (at boiler wall } \\
\text { temp. for Tests } \\
\text { i-iii and bulk } \\
\text { fluid temp for } \\
\text { Test iv) }(-)\end{array}$ & $\begin{array}{c}\text { Boiler } \\
\text { flow } \\
\text { temperatu } \\
\left.\text { re } \mathbf{(}^{\circ} \mathbf{C}\right)\end{array}$ & $\begin{array}{c}\text { Boiler return } \\
\text { temperature } \\
\left({ }^{\circ} \mathbf{C}\right)\end{array}$ & $\begin{array}{c}\text { Pipe work } \\
\text { internal } \\
\text { diameter } \\
(\mathbf{m m})\end{array}$ \\
\hline I_VSG1 & 0.52 & 2.7 & $7.5-21.5$ & 1.1 & $82-64$ & 55 & 20 \\
\hline II_VSG1 & $0.25-0.52$ & 2.7 & 10 & 1.1 & 80 & $55-68.4$ & 20 \\
\hline III_VSG1 & 0.52 & 2.7 & 17 & $1.0-1.2$ & 75 & 55 & 20 \\
\hline IV_HSG1\&2 & $0.25-0.52$ & 2.7 & 10 & 0.89 & 80 & $55-68.4$ & 20 \\
\hline
\end{tabular}

Table 1: Experimental parameters 
The heat transfer coefficient in Eqn. (9) was calculated using a correlation for predicting the Nusselt number in helical coils as given in Eqn. (10) [19].

$$
N u=0.00619 \operatorname{Re}^{0.92} \operatorname{Pr}^{0.4}\left(1+3.455 \frac{d_{h}}{D_{c}}\right)
$$

The experimental conditions used in the present study are within the correlation validity range;

$$
5 \times 10^{3}<\operatorname{Re}<10^{5}, 0.7<\operatorname{Pr}<5,0.0267<\frac{d_{h}}{D_{c}}<0.0884
$$

Standard central heating systems make use of untreated steel radiators and copper piping. The untreated radiators result in a limited amount of oxidation due to the dissolved oxygen present in the tap water. The oxidation process releases iron oxide and some hydrogen gas. The analysis of dissolved gases through the use of Orbisphere 3655 oxygen and Orbisphere 3654 hydrogen sensors resulted in very low concentrations of oxygen and hydrogen present in their dissolved form. In fact, both gases were present in concentrations of circa 9 PPB. Therefore, nitrogen is evidently the dominant gas and its properties were used for the dissolved gas properties in this study. As illustrated in Fig. 2 , three square sight glasses with internal dimensions of $20 \times 20 \mathrm{~mm}$ were used for filming micro bubbles at the exit line of the boiler and in the horizontal flow line. A square section was designed to reduce the distortion as a result of viewing bubbles through a curved surface. As discussed by Prodanovicet al. [20], such distortions are due to light refraction. A Vision research Phantom V5 high speed camera connected to a PC was used to film and store the video clips. A monozoom (Navitar) microscope lens was used to develop the desired magnification and a shutter speed of $30 \mu \mathrm{s}$ and a frame speed of 100 frames per second was used. Lighting was provided by two high intensity Everest.VIT ELSV $60 \mathrm{~W}$ light sources attached to semi rigid fibre optic light guides. Due to the relatively small bubbles present in this system [21] the bubble distribution in at the boiler exit (VSG1) was assumed to be quasi uniform across the vertical pipe section. However, bubble stratification in the horizontal pipes due to gravitational effects required the use of 5 focal planes at a depth of $1,4,8,12,16 \mathrm{~mm}$ for sight glasses HSG1\&2. (Fig.3)

\subsection{Image analysis}

The video films were converted to image frames saved as 'tag image file format' or tiff files using the Phantom Version 606 camera software. The bubble production rates and diameters were calculated through the use of the image analysis software, ImagePro Plus developed by Media Cybernetics. A macro was written enabling a series of images to be analysed for in focus bubble counts and diameters. The macro included the use of a Sobel filter to enable the distinction between in and out of focus bubbles. The Sobel filter plots the gradient of the intensity change between objects and their background through the extraction and enhancement of edges and contours. This is done by expressing intensity differences or gradients between neighbouring pixels as an intensity value. 


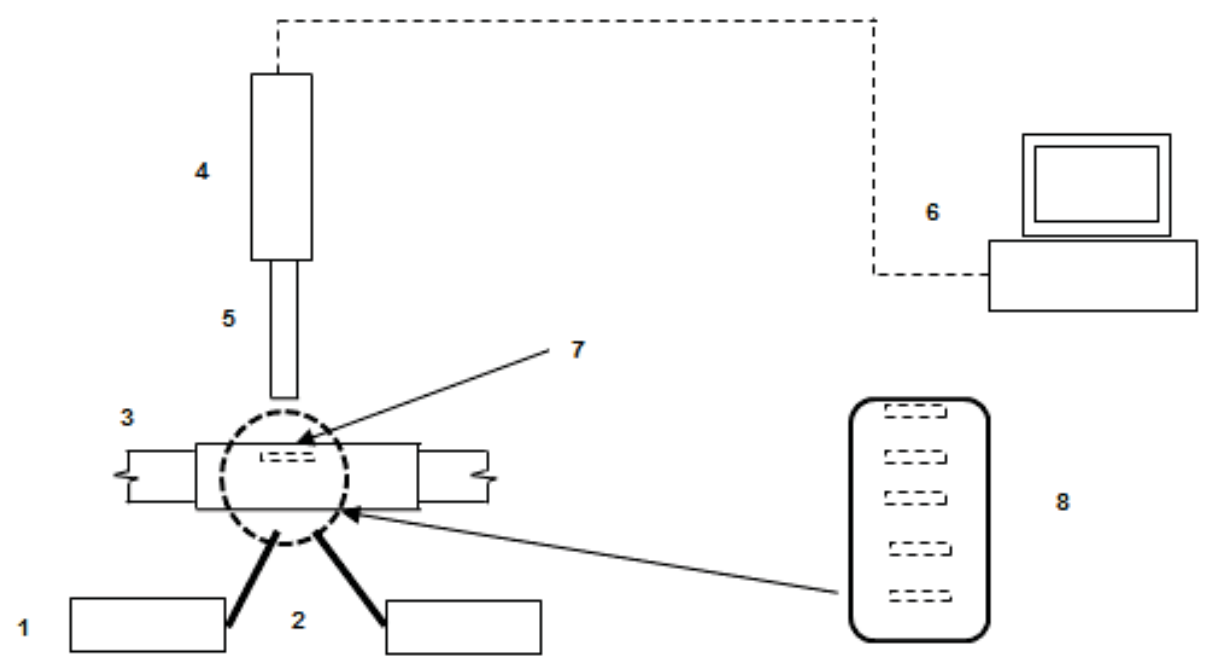

1. Light sources

2. Fibre optic light guide

3. Square sight glass section $(20 * 20 \mathrm{~mm})$

4. High speed camera
5. Microscope lens

6. PC wired to camera

7. Focal depth of $1.5 \mathrm{~mm}$

8. 5 focal planes at $0,4,8,12,16 \mathrm{~mm}$ from the top of sight glass

Figure 3: Imaging equipment (setup for horizontal sight glasses - HSG1\&2)

Therefore, objects that are in focus have sharp edges with a high gradient change and consequently result in a high intensity values, whereas out of focus objects do not display such a characteristic. The Sobel filter was used as it is less sensitive to image noise when compared to other filtering techniques. [22] A typical analysed image is illustrated in Fig. 4, where in focus bubbles are circled. Experimental uncertainties were calculated based on the method given by Coleman and Steel [23] and estimated as a mean absolute value of $12 \%$ for the bubble production rates and $7.1 \%$ for the bubble size ratio.

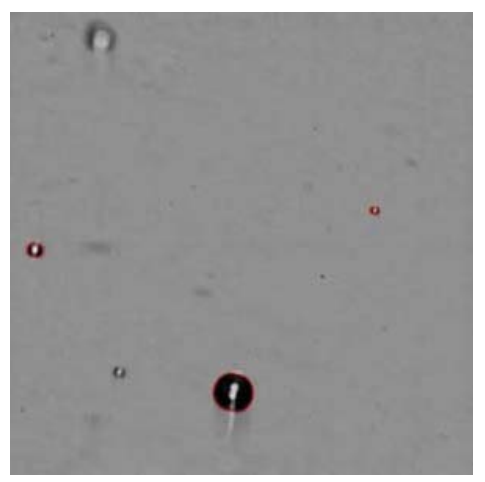

Figure 4: Typical camera images (post processing with in focus bubbles circled) 


\section{RESULTS AND DISCUSSION}

\subsection{Bubble production rates measured at boiler exit}

An average of 1500 frames for each experimental run were analysed through the use of the image processing software.A good representation of the total bubble production rate from the heat exchanger surface with respect to the parameters as shown in Table 1 is given in Figs. 5\&6. Bubble distribution tests across the sight glass section have shown quasi uniform bubble concentrations and void fractions. This is in agreement with the findings by Liu [24] who reported that in vertical two phase pipe bubbly flow characterised with small bubble diameters, uniform distributions are more likely across the pipe section. Bubbles with average diameters within the range of 0.13 and $0.39 \mathrm{~mm}$ were observed in our system. [21] Similar assumptions were made by Winterton and Munaweera[4] through their study for bubbly flow in ducts. Through the knowledge of the sample image volume, sight glass dimensions, system flow rate and camera speed in frames per second it was possible to calculate the rate of bubbles produced per second of system operation. Coalescence and breakup at the boiler exit were assumed to be negligible due to the small bubble size [3] and due to the low nucleation rates which renders the possibility of bubble collision at the exit of the heat exchanger as unlikely. [7] Furthermore, the bubble dissolution rates were also assumed to be negligible due to adiabatic conditions at the exit of the heat exchanger and due to the relatively small temperature difference between the bulk fluid and the heat exchanger wall. In fact, an average temperature difference of $10^{\circ} \mathrm{C}$ was calculated.

The experimental results have shown that the nucleation rate increased with;

- Increasing heat flux

- Increasing super saturation levels

- Increasing bulk fluid velocity

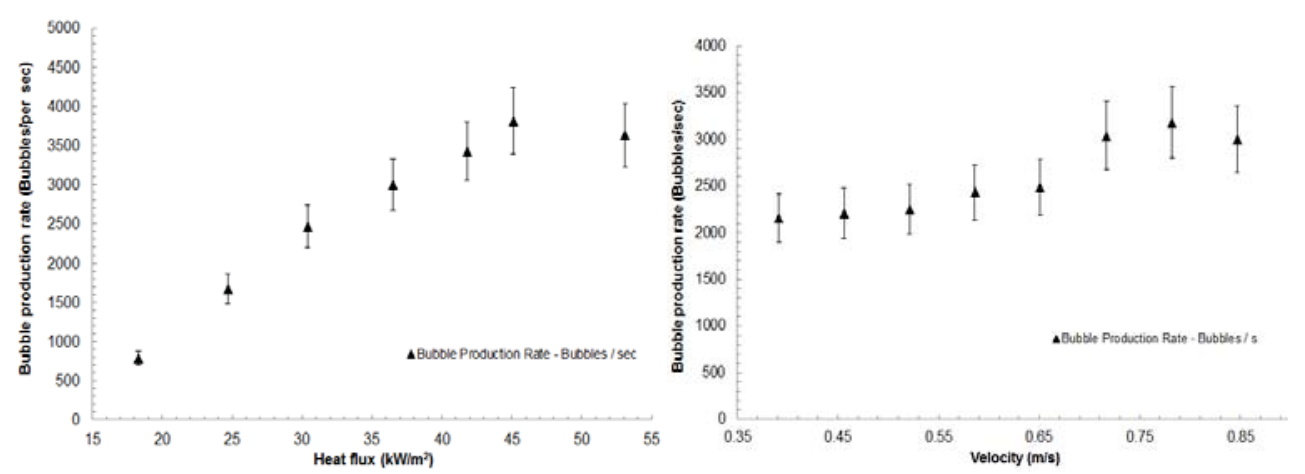

Figure 5: Bubble production rates measured at boiler exitfor Tests I (Left) \&ll (Right) 


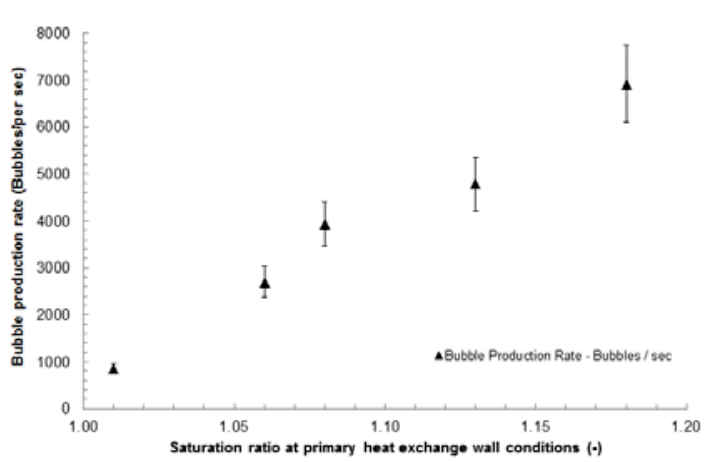

Figure 6: Bubble production rates measured at boiler exit for Test III

The results presented in Figs $5 \& 6$ are in line with bubble nucleation theory. $[3,6,7,8,9]$ An increase in the saturation ratio results in an increase in the dissolved gas concentration gradient, thus enabling a higher nucleation rate per unit heat exchanger area whereas higher heat flux levels or system heating loads resulted in higher heat exchanger wall temperatures, consequently increasing the dissolved gas diffusivity. Therefore, as predicted by Hepworth et al [3], this leads to an increase in the resultant bubble nucleation rate per unit area of the heat exchanger under super saturation conditions. Furthermore, higher liquid velocities increase the mass transfer coefficient for gas entering the bubble from the bulk liquid thus increasing the nucleation rate, thus increasing the overall bubble production rate. [3] An increase in the bulk fluid velocity also results in a decrease in the resultant bubble detachment radius $[11,21]$ and therefore, a higher concentration gradient of gas is assumed to be present at the primary heat exchanger surface, thus enabling more bubbles to be released from the heat exchanger surface at a given time instant.

\subsection{Bubble dissolution in horizontal pipes}

A good representation for the reduction in the mean bubble diameter in horizontal pipe flow with respect to the experimental parameters as illustrated in Table I (Test IV) and represented through the ratio $R_{x} / R_{0}$ is given in Fig. 7 (Left) while the ratios measured at the five focal planes across the pipe depth are given in Fig. 7 (Right). The experimental results are in reasonable agreement with the expected trends whereby smaller bubbles were observed at HSG2in relation to HSG1 due to bubble dissolution at under saturation bulk fluid conditions. A direct comparison with experimental data and dissolution mathematical models available in literature sources is not possible as very limited consideration has been given by literature to similar physical conditions. As discussed in Section 2 of the present study, most bubble dissolution experimental studies and related mathematical models were done for isolated bubbles under stagnant fluid conditions or for stationary bubbles on a wall under a bulk fluid flow. Hence, the gap in the available literature on dissolution data and models for free moving bubbles in bubbly flows.

Fig. 7 suggests a minimal decrease in the resultant bubble dissolution rate with a reduced velocity. The reduction in the bulk fluid velocity from a maximum of $0.52 \mathrm{~m} / \mathrm{s}$ to $0.25 \mathrm{~m} / \mathrm{s}$ doubled the time for the bubble to flow through the pipe section under 
consideration. Hence, assuming that the bulk fluid turbulence effects are ignored a reverse result is expected due to the increased time lag for bubbles to move between the two sight glasses, thus allowing more gas to diffuse out of the bubbles. Therefore, the results of the present study suggest that the increase in the turbulent intensity enhances the dissolution rate, thus overriding the effects expected by the increase in the time lag. The relative velocity between the bubbles and the bulk liquid phase was calculated to be in the range of 0.0002 to $0.00009 \mathrm{~m} / \mathrm{s}$ [25]. Therefore, the velocity gradient experienced by the bubbles can be assumed to be negligible for the purposes of the present study.
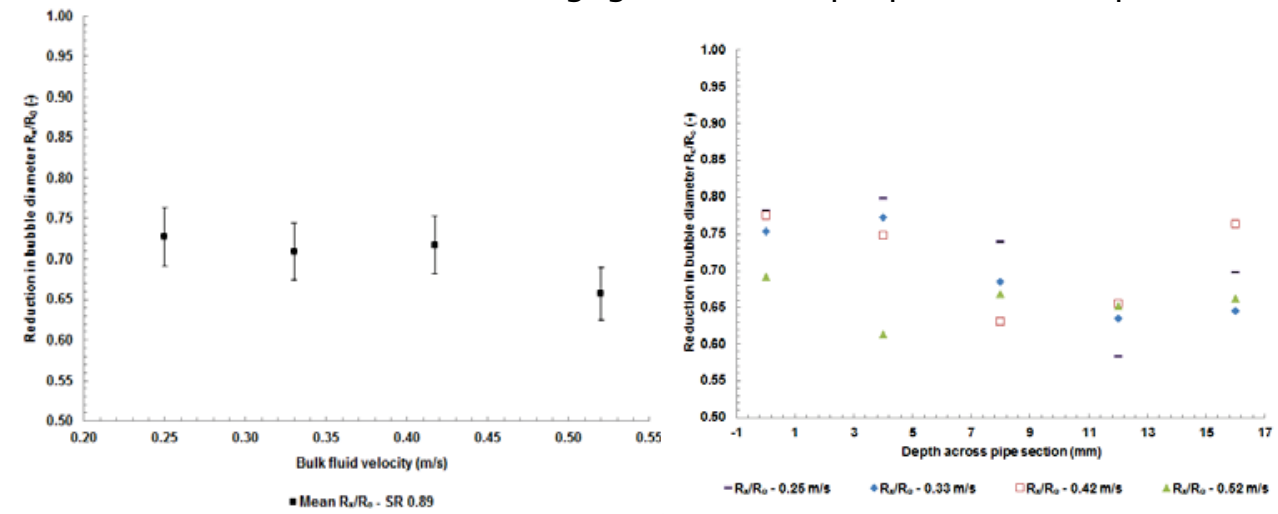

Figure 7: Mean $R_{x} / R_{\circ}$ with bulk fluid velocity and constant under saturation conditions (Left) and $R_{x} / R_{0}$ with pipe depth (Right) (Test IV)

Hence, it can be assumed that the turbulent intensity enhances the concentration gradient around the bubble which is free flowing in the liquid, thus leading to the phenomenon of turbulent diffusion as classified by Lezhnin et al. [13]. These results contrast to the findings by Shedd[26] who stated that for free bubbles dissolving in a bubbly flow, it would be reasonable to use the pure diffusion model, thus assuming stagnant conditions with no relative velocity present between the two phases.

\subsection{Correlation of data for bubble dissolution tests}

To correlate the predicted bubble radius in horizontal pipe flow in a domestic central heating system, the Epstein and Plesset[14] model for bubble dissolution was adopted as in Eqn. (11). As this model was developed for isolated bubbles in a stagnant pool of water, the dimensionless Sherwood number was included to capture the turbulent diffusion process due to the convective mass transfer from the bubble to the liquid. The empirical correlation identified by Lezhnin et al. [13] for the calculation of the Sherwood number was used as given in Eqn. (5). The correlation proportionality constant was optimised through the iteration method.

$$
\epsilon^{2}=1-\operatorname{Sh}\left[x^{2}\right]
$$

Where the proportionality constant for the Sherwood number; $A=0.17$ 
The correlation data is compared to the experimental data for all the tests done with varying under saturation ratios and bulk fluid velocities as illustrated in Fig. 8 . The correlationpredicted the expected bubble radius after a measured time $t$ with a mean absolute error of $10 \%$. Furthermore, $96 \%$ of the data points are between $\pm 20 \%$ of the new correlation predictions.

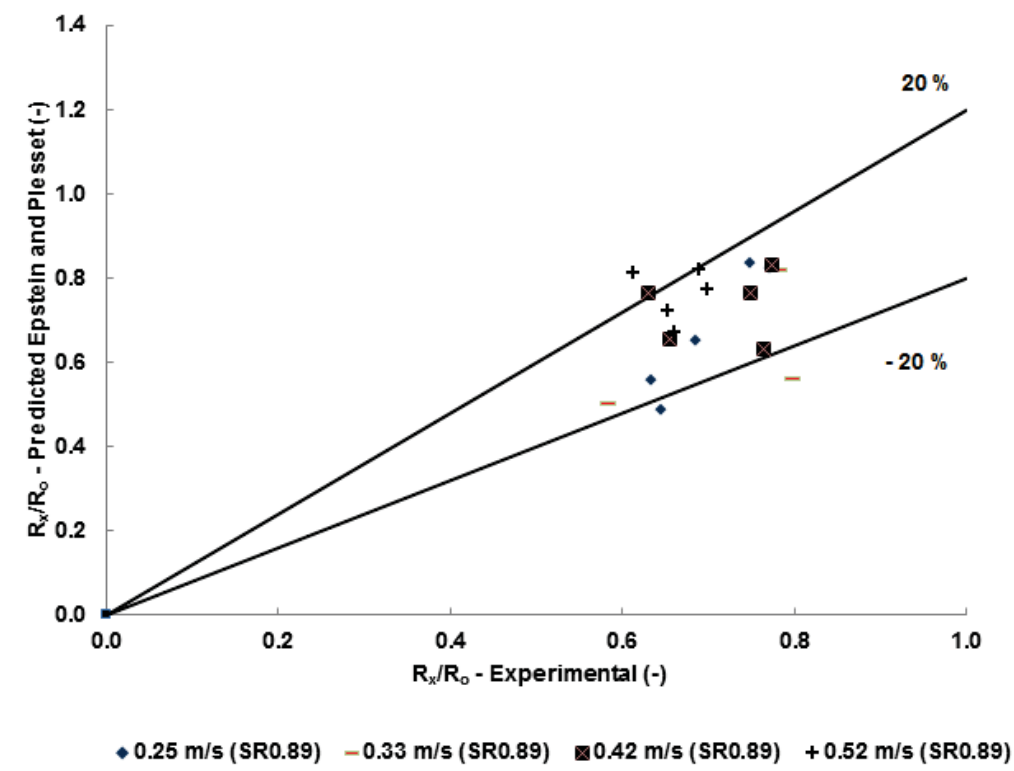

Figure 8: Error plot for Epstein and Plesset correlation and present study experimental results

\section{Conclusions}

This paper has presented an experimental study on the typical micro bubble production rates at the primary heat exchanger of a domestic central heating system due to gas super saturation conditions. A range of 784 to 6920 bubbles per sec was measured with system conditions with the mean average bubble diameter being in the range of 0.05 to $0.39 \mathrm{~mm}$. The bubble production rate is mainly dependent on the dissolved gas concentration levels, heat flux and bulk fluid velocity.

The dissolution of free bubbles in turbulent horizontal bubbly flow in under saturated water conditionswas also investigated. The maximum dissolution rate measured for the bubble size ratios is $12 \%$ per second or $18 \%$ per meter of horizontal pipe work with system conditions. The dissolution mechanism is mainly dependent on the gas concentration in the bulk fluid and the turbulent intensity. The importance of this study lies with the fact that a comprehensive understanding of the dissolution of micro bubbles in central heating systems should lead to an optimised deaeration system thereby improving the overall system performance, thus reducing the extensive carbon footprint of such systems. The present study has suggested a new correlation for wet central heating systems based on the Epstein and Plesset isolated bubble dissolution model with the inclusion of the Sherwood number to incorporate the effects of turbulent diffusion on the mass transfer process. 


\section{Notation}

A Proportionality constant, (-)

$C_{E} \quad$ Gas concentration in bubble, $\left(\mathrm{kg} / \mathrm{m}^{3}\right)$

$C_{O} \quad$ Gas concentration in bulk liquid, $\left(\mathrm{kg} / \mathrm{m}^{3}\right)$

$C_{g a s}$ Gas concentration in system, (standard $\mathrm{cm}^{3} /$ Litre water)

$C_{\text {sat }}$ Maximum gas concentration at the primary heat exchanger wall temperature or bulk fluid conditions, (standard $\mathrm{cm}^{3} /$ Litre Water)

$d \quad$ Pipe diameter, $(\mathrm{m})$

$d_{\text {bub }} \quad$ Bubble diameter, $(\mathrm{m})$

$d_{h} \quad$ Heating tube hydraulic diameter, $(\mathrm{m})$

$D$ Diffusivity, $\left(\mathrm{m}^{2} / \mathrm{s}\right)$

$D_{c} \quad$ Helical coil diameter, $(\mathrm{m})$

$h \quad$ Heat transfer coefficient, $\left(\mathrm{W} / \mathrm{m}^{2} \mathrm{~K}\right)$

$\mathrm{Nu} \quad$ Nusselt number, (-)

$P_{g} \quad$ Partial pressure of dissolved gas, $(\mathrm{Pa})$

$\mathrm{Pr} \quad$ Prandtl number, (-)

$q \quad$ Heat flux, $\left(\mathrm{kW} / \mathrm{m}^{2}\right)$

$R \quad$ Gas constant, (J/mol K)

$R_{o} \quad$ Original bubble radius at HSG1, $(\mathrm{m})$

$R_{x} \quad$ Final bubble radius at HSG2, $(\mathrm{m})$

$R e \quad$ Reynolds number, (-)

Sc Schmidt number, (-)

Sh Sherwood number, (-)

$t \quad$ Time, (s)

$T_{b} \quad$ Bulk fluid temperature, $(\mathrm{K})$

$T_{w} \quad$ Fluid temperature at the primary heat exchanger wall conditions, $(\mathrm{K})$

$X_{b} \quad$ Bulk fluid gas concentration, $\left(\mathrm{mol} / \mathrm{m}^{3}\right)$

$X_{i} \quad$ Saturation gas concentration, $\left(\mathrm{mol} / \mathrm{m}^{3}\right)$

$X^{T} \quad$ Gas solubility factor, (standard $\mathrm{cm}^{3} /$ Litre water/bar)

\section{Greek letters}

$a \quad$ Saturation ratio, (-)

$\rho_{g}$ Gas density, $\left(\mathrm{kg} / \mathrm{m}^{3}\right)$

$\sigma \quad$ Super saturation ratio, (-)

\section{ACKNOWLEDGEMENTS}

The authors would like to thank the Engineering and Physical Science Research Council, STEPS Malta, and Spirotech b v., the Netherlands, for supporting this research work. 


\section{REFERENCES}

[1] Gerrard W.:Solubility of gases and liquids, New York, Plenum Press, 1976.

[2] Young C.L., Battino R., Clever H.L.: The solubility of gases and liquids introductory information, Nitrogen and Air, solubility data series - Volume 10, Oxford, Pergamon Press, 1982.

[3] Hepworth N.J., Boyd J.W.R., Hammod J.R.M., Varley J.: Modelling the effect of liquid notion on bubble nucleation during beer dispense, Chemical Engineering Science, 58 (2003) 4071 - 4084.

[4] Winterton R.H.S., Munaweera J.S.: Bubble size in two-phase gas-liquid bubbly flow in ducts, Chemical Engineering and Processing, 40 (2001) 437 - 447.

[5] The Building Regulations, Conservation of Fuel and Power - Part L1A, Office of the Deputy Prime Minister, 2006.

[6] Wilt P.M.: Nucleation rates and bubble stability in water-carbon dioxide solutions, Journal of Colloid and Interface Science, 112 (1986) $530-538$.

[7] Lubetkin. S., Blackwell M.: The nucleation of bubbles in supersaturated solutions, Journal of Colloid and Interface Science, 26 (1988) 610-615.

[8] Carr M.W. Hillman A.R., Lubetkin S.D.: Nucleation rate dispersion in bubble evolution kinetics, Journal of Colloid and Interface Science, 169 (1995) 135 142.

[9] Jones S.F., Evans G.M., Galvin K.P.: The cycle of bubble production from a gas cavity in a supersaturated solution, Advances in Colloid and Interface Science, 80 (1999a) 27 - 50.

[10] Jones S.F., Evans G.M., Galvin K.P.: Bubble Nucleation from Gas Cavities - A Review, Advances in Colloid and Interface Science, 80 (1999b) 51 - 84.

[11] Winterton R.H.S.: Sizes of bubbles produced by dissolved gas coming out of solution on the walls of pipes in flowing Systems, Chemical Engineering Science, 27 (1972) 1223-1230.

[12] Kress T.S., Keyes J.J.: Liquid phase controlled mass transfer to bubbles in cocurrent turbulent pipeline flow, Chemical Engineering Science, 28, (1973) 18091823.

[13] S. Lezhnin, EskinD., Leonenko Y., Vinogradov O.: Dissolution of air bubbles in a turbulent water pipeline flow, Heat and Mass Transfer, 39, (2003) 483-487.

[14] P.S. Epstein, M.S. Plesset: Heat or mass transfer-controlled dissolution of an isolated sphere, The Journal of Chemical Physics, 18(11) (1950) 1505 1509.

[15] Duda J.L., Vrentas J.S.: Heat or mass transfer-controlled dissolution of an isolated sphere, Int. J. Heat Mass Transfer, 14 (1971) 395 - 408.

[16] Cable M., Frade J.R.: The influence of surface tension on the diffusion-controlled growth or dissolution of spherical gas bubbles, Proc. R. Soc. Lond, A420 (1988) $247-265$.

[17] Fogg P.T.G.: Some Aspects of the Solubility of Gases in Liquids, MonatsheftefürChemie, 134, pp. 619 - 631, 2003.

[18] Lamers A.:Langdurigeexperimentenketelproefstand, Unpublished research, Spirotech R\&D, (2005). 
[19] Xin R.C., Ebadian M.A.: The effects of Prandtl number on local and average convective heat transfer characteristics in helical pipes, Journal of Heat Transfer, 119 (1997) 467-473.

[20] Prodanovic V., Fraser D., Salcudean M.: Bubble behaviour in sub cooled Flow Boiling of water at low pressures and low flow rates, International Journal of Multiphase Flow, 28 (2001) 1-19.

[21] Fsadni A.M., Ge Y.T., Lamers A.G.: Measurement of bubble detachment diameters from the surface of the boiler heat exchanger in a domestic central heating system,AppliedThermal Engineering, Volume 31, Issues 14-15, (2011) Pages 2808-2818.

[22] Image-Pro Plus Start-Up Guide, MediaCybernetics, 2010

[23] Coleman H.W., Steele, W.G.:Experimentation and uncertainty analysis for engineers, $2^{\text {nd }}$ ed., John Wiley\& Sons Inc., New York, 1999.

[24] Liu T.J.: Bubble size and entrance length effects on void development in a vertical channel, Int. J. Heat and Mass Transfer, 19 (1993) 99-113.

[25] Adrian R.J.: Particle-imaging techniques for experimental fluid mechanics, Annual Review of Fluid Mechanics, 23 (1991) 261 - 304.

[26] Shedd T.A.: General model for estimating bubble dissolution and droplet evaporation times, Chemical Engineering Science, 4(3) (2005) 033004-1-8. 